\title{
Relationship of small bowel motility to ileoanal reservoir function
}

\author{
J S Groom, M A Kamm, R J Nicholls
}

\begin{abstract}
Some patients with an ileoanal reservoir have a high defecation frequency, despite a good anatomical result and the absence of pouchitis. This study aimed to determine whether variation in function is related to a difference in small bowel motility proximal to the reservoir and if small bowel motility is propagated into the reservoir. Ambulatory small bowel and reservoir motility was studied for 24 hours in five patients with good function (median bowel frequency 4 per day, range 3-6) and seven subjects with poor function (median bowel frequency 12 per day, range 10-20). Five solid state pressure sensors were positioned in the small bowel and one in the reservoir. During the fasting nocturnal period $(2300-0800 \mathrm{~h}$ ), patients with poor function had a median of 10 (range 5-13) migrating motor complexes (MMC), significantly greater $(p=0.03)$ than the corresponding median number of 3 (range 2-7) in patients with good function. A total of 120 MMCs were observed in the whole series of 12 patients. Of these only two were propagated from the small bowel into the reservoir. Discrete clustered contractions were not propagated into the reservoir, although prolonged propagated contractions did pass into the reservoir in one patient. Patients with poor function had similar 24 hour stool output and radiological reservoir size to those with good function, but the median maximum tolerated volume on reservoir distension was $290 \mathrm{ml}$ (range 160-450) for patients with poor function compared with $475 \mathrm{ml}$ (range 460-550) for patients with good function $(p=0.005)$. Small bowel motility proximal to the reservoir bears an important relationship to pouch function and defecation frequency. Propagation of coordinated proximal small intestinal motility into the reservoir is rare.

(Gut 1994; 35: 523-529)
\end{abstract}

Restorative proctocolectomy is now well established in the management of ulcerative colitis and familial adenomatous polyposis. Most patients have good function with a bowel frequency of six or fewer motions per 24 hours, the ability to defer defecation, and good continence.

A few patients, however, have a poor functional result, especially high stool frequency, despite having a reservoir of good capacity, normal sphincter function, and no inflammation. ${ }^{23}$

The high frequency in these cases might be explained by a large stool volume. Alternatively, small bowel motility characteristics may be different to those with a lower frequency of defecation. There is, however, little data to support this view. We have previously studied prolonged ambulatory reservoir motility in 12 patients. ${ }^{4}$ The major features of the recordings were large isolated contractions, periods of rhythmic activity lasting 18 seconds to 18 minutes, and random isolated contractions. The same pattern of motor activity was observed in patients with good and poor function, although the number of patients studied with poor function was small, possibly obscuring quantitative differences. Lastly, there may be differences in small bowel motility proximal to the reservoir which influence reservoir behaviour.

The origin of periods of rhythmic reservoir activity is unknown. They may originate in the reservoir itself, deriving from the myenteric plexus of the reservoir ileum in isolation from the proximal anatomically intact ileum. Alternatively, they may be clustered contractions or migrating motor complexes (MMCs) which have been propagated from the proximal small bowel into the reservoir. A third possibility, that small intestinal motility proximal to the reservoir is a factor influencing frequency, has not been formally studied.

This study aimed to determine whether small bowel motility is an important factor in the frequency of defecation after an ileoanal reservoir has been created. Small bowel and reservoir motility were compared in two groups of patients who were prospectively selected as having a low or high bowel frequency. We also wished to determine whether proximal small bowel motility was propagated into the reservoir and whether the presence or absence of such propagation influenced the clinical outcome.

\section{Subjects and methods}

\section{SUBJECTS}

Twelve patients were prospectively selected for the study on the basis of their clinical function (Table I).

\section{Good function (low defecation frequency)}

These patients had six or less bowel actions for 24 hours without medication, incontinence restricted to minor episodes of soiling not more than once per week, were able to defer defecation for more than 60 minutes, and were able to defecate spontaneously.

Five patients with good function (three men, two women) aged 32-56 (median 46) years were studied 15-64 months (median 24) after ileostomy closure. Three had $\mathrm{W}$ reservoirs, one a J reservoir, and one an ileoanal Kock reservoir. The original disease was ulcerative colitis in four and familial adenomatous polyposis in one. 
TABLE I Bowel frequency, anal manometry, and pouch sensation in patients with good and poor pouch function (oalues, median (range))

\begin{tabular}{|c|c|c|c|}
\hline & $\begin{array}{l}\text { Good fronction } \\
(n=5)\end{array}$ & $\begin{array}{l}\text { Poor function } \\
(n=7)\end{array}$ & $p$ \\
\hline $\begin{array}{l}\text { Bowel function: } \\
\text { Bowel actions (24 h) } \\
\text { Stool vol (m1/24 h) } \\
\text { Each stool (ml) }\end{array}$ & $\begin{array}{l}4(3-6) \\
887(615-1025) \\
140(50-350)\end{array}$ & $\begin{array}{c}12(10-20) \\
915(850-996) \\
88(40-200)\end{array}$ & $\begin{array}{l}0.003 \\
1 \cdot 11 \\
0.01\end{array}$ \\
\hline $\begin{array}{l}\left.\text { Anal manometry (cm } \mathrm{H}_{2} \mathrm{O}\right) \text { : } \\
\text { Resting anal pressure } \\
\text { Voluntary contraction } \\
\text { Reservoir sensation: }\end{array}$ & $\begin{array}{c}60(40-80) \\
120(60-200)\end{array}$ & $\begin{array}{c}50(30-60) \\
100(40-180)\end{array}$ & $\begin{array}{l}0.27 \\
0.64\end{array}$ \\
\hline $\begin{array}{l}\text { Threshold (ml) } \\
\text { Urge (ml) } \\
\text { MTV (ml) }\end{array}$ & $\begin{array}{l}133(60-220) \\
190(120-350) \\
475(460-550)\end{array}$ & $\begin{array}{l}110(15-150) \\
120(55-250) \\
290(160-450)\end{array}$ & $\begin{array}{l}0.3 \\
0.53 \\
0.005\end{array}$ \\
\hline
\end{tabular}

MTV=maximum tolerated volume.

\section{Poor function (high defecation frequency)}

Seven subjects with poor function were studied 9-108 (median 26) months after ileostomy closure. There were three women and four men aged 29-62 (median 51) years. Each had 10 or more bowel actions per 24 hours (range 10-20, median 12) and all were on antidiarrhoeal medication. Antidiarrhoeal drugs were stopped 48 hours before the study. Two patients had a $W$ reservoir and five a $J$ reservoir. The original disease was ulcerative colitis in six patients and familial adenomatous polyposis in one. No patient had pouchitis at the time of the study, as judged by lack of endoscopic and histological inflammation.

The study was approved by the City and Hackney Ethics Committee, and all subjects gave informed consent.

\section{METHODS}

\section{Equipment}

To record small bowel motility, a $3 \mathrm{~mm}$ diameter pliable catheter $300 \mathrm{~cm}$ in length was used
(Gaeltec Limited, Dunvegan, Isle of Skye, Scotland). This catheter contained five solid state pressure transducers located at $20 \mathrm{~cm}$ intervals from the distal tip: the transducers thereby spanning a distance of $80 \mathrm{~cm}$. A small inflatable balloon was attached to the end of the catheter, with a $1 \mathrm{~mm}$ diameter tube taped onto the side of the catheter for balloon inflation and deflation.

Subjects were intubated via the nasointestinal route after an overnight fast. Radiological screening confirmed the passage of the catheter past the pylorus, at which time the balloon at the end of the catheter was inflated with $10 \mathrm{ml}$ of air. Approximately 24 hours were required for the catheter to reach its final position. The catheter was inserted for $250 \mathrm{~cm}$. The course of the catheter was monitored fluoroscopically. The final position of the catheter was confirmed with fluoroscopic screening, at which time the balloon was deflated. The position of the distal tip of the catheter was approximately 20 to $30 \mathrm{~cm}$ from the reservoir (Fig 1). The probe did not reach the reservoir in any patient.

Once the small bowel catheter was in place, a second catheter was inserted per anum into the reservoir. This catheter had a solid state pressure trandsducer $1 \mathrm{~cm}$ from the tip.

Both pressure catheters were connected to a 7-channel Gaeltec portable recorder with 512 kBite digital memory. Pressures were sampled in each channel at a frequency of $8 / \mathrm{s}$. When the pressure did not deviate more than $2 \mathrm{~cm} \mathrm{\textrm {H } _ { 2 }} \mathrm{O}$ from the previous pressure value that data point was not stored, allowing data compression. With seven channels recording, this allowed approximately eight hours of continuous recording before downloading to a computer was required for further data acquisition to continue. The recorder was carried as a shoulder bag, and had a patient-initiated event marker button.

\section{Conditions of study}

Recording started on the second day, when both probes were in the correct position. Patients were fully ambulant during the study and on an unrestricted diet. Each patient kept a diary of their activities and was instructed to note times and composition of oral intake, time and characteristics of episodes of defecation, and time and nature of any abdominal symptoms. The volume of stool passed on each occasion was also recorded. Occasionally the pouch probe was dislodged during defecation, but was immediately replaced when this occurred.

At the completion of the study standard laboratory static measurements of anal manometry and pouch pressure-volume characteristics were assessed, using methods previously described. ${ }^{5-6}$ Anal manometry was performed with a closed, water-filled microballoon using a stationary pull-through technique. The maximum resting pressure and the maximum squeeze pressure were both determined, the latter recorded as the increment above the resting pressure.

Pouch pressure-volume characteristics were measured using a compliant condom filled with water at a constant rate of $50 \mathrm{ml} / \mathrm{min}$. The distending balloon reached a maximum pressure of $20 \mathrm{~cm} \mathrm{H}_{2} \mathrm{O}$ ex vivo. The volumes and pres-
Figure 1: Example of small bocwel and reserooir pressure recording ooer 120 mimutes in a patient with poor pouch fronction. Four migrating motor complex (MMC) cycles within the small bowel are seen. Betroeen the second and third MMC cycle the patient strained at defecation causing increased activity in all chanonels. The pouch probe came out during defecation but was replaced imomediately afierwards. 
TABLE II Reserooir pressure-oolume characteristics in patients with good and poor function (oalues, median (range))

\begin{tabular}{|c|c|c|c|}
\hline & \multicolumn{3}{|c|}{ Pouch pressure/oolume ( $\left.\mathrm{cm} \mathrm{H}_{2} \mathrm{O} / \mathrm{ml}\right)$} \\
\hline & $\begin{array}{l}\text { Good function } \\
(n=5)\end{array}$ & $\begin{array}{l}\text { Poor function } \\
(n=7)\end{array}$ & $\begin{array}{l}p \\
\text { Dalue }\end{array}$ \\
\hline $\begin{array}{l}\text { Reservoir sensation: } \\
\text { Threshold } \\
\text { Urgency } \\
\text { MTV }\end{array}$ & $\begin{array}{ll}0.06 & (0.02-0.44) \\
0.06 & (0.02-0.20) \\
0.07 & (0.01-0.16)\end{array}$ & $\begin{array}{l}0.62(0.01-3.30) \\
0.54(0.04-1.45) \\
0.29(0.03-0.37)\end{array}$ & $\begin{array}{l}0.5 \\
0 \cdot 2 \\
0 \cdot 2\end{array}$ \\
\hline $\begin{array}{l}\text { Reservoir distension volume: } \\
100 \mathrm{ml} \\
200 \mathrm{ml} \\
300 \mathrm{ml}\end{array}$ & $\begin{array}{l}0.11(0.05-0.8, n=5) \\
0.07(0.02-0.4, n=5) \\
0.03(0.02-0.7, n=4)\end{array}$ & $\begin{array}{l}0.75(0.05-0.5, n=7) \\
0.05(0.05-0.2, n=5) \\
0.1(0.05-0.2, n=3)\end{array}$ & $\begin{array}{l}0 \cdot 6 \\
0 \cdot 8 \\
0 \cdot 1\end{array}$ \\
\hline
\end{tabular}

This table shows that differences in function between the two groups of patients did not relate to differences in pouch sensory function or tension characteristics.

TABLE III Nocturnal (2300-0800 h) small bowel motility in pouch patients with good and poor function (values, median (range))

\begin{tabular}{lcll}
\hline & $\begin{array}{l}\text { Good function } \\
(n=5)\end{array}$ & $\begin{array}{l}\text { Poor function } \\
(n=7)\end{array}$ & $p$ \\
\hline MMCs: & & & \\
Propagating MMCs & 16 & 53 & \\
Non-propagating MMCs & 4 & 66 & \\
Total & 20 & $10(5-13)$ & $0 \cdot 03$ \\
No of MMC/subject & $3(2-7)$ & $64(45-86)$ & $0 \cdot 06$ \\
Duration MMC cycle (min) & $94(88-98)^{\star}$ & $5(2-9)$ & $0 \cdot 61$ \\
Velocity of MMC (cm/min) & $5(4-6)$ & $49(34-67)$ & $0 \cdot 04$ \\
Interdigestive phase duration: & $80(67-86)$ & $7(0-12)$ & $0 \cdot 55$ \\
Phase 1 (min) & $4(3-5)$ & $8(6-12)$ & $0 \cdot 48$ \\
Phase 2 (min) & $6(3-8)$ & & \\
Phase 3 (min) & & & \\
\hline
\end{tabular}

^In two patients with good function there were not enough MMC cycles for comparison. MMC= migrating motor complex.

TABLE IV Features of nocturnal migrating motor complexes (MMC) in pouch patients with good and poor function

\begin{tabular}{llll}
\hline & $\begin{array}{l}\text { Good function } \\
(n=5)\end{array}$ & $\begin{array}{l}\text { Poor function } \\
(n=7)\end{array}$ & $p$ \\
\hline Propagating MMCs: & 16 & 53 & \\
Total no & $11(69 \%)$ & $41(77 \%)$ & \\
No reaching distal transducer & $\begin{array}{l}\text { was first detected: } \\
\text { Most proximal sensor at which }\end{array}$ & $23(43 \cdot 4 \%)$ & \\
p1 (proximal) & $7(43 \cdot 7 \%)$ & 24 & $0 \cdot 7 \star$ \\
p2 & 7 & 3 & $0 \cdot 4$ \\
p3 & 2 & 3 & \\
p4 (distal) & 2 & & \\
Non-propagating MMCs: & & 13 & \\
Total no & 4 & & \\
No subject (median) & & 3 & $0 \cdot 7 \star$ \\
Site of non-propagating MMC: & 0 & 5 & \\
p1 & 2 & 3 & \\
p2 & 0 & 7 & \\
p3 & 1 & & \\
p4 & 1 & & \\
p5 & & & \\
\end{tabular}

${ }^{\star} \chi^{2}$ analysis. formed manually by reviewing all records in their entirety on the screen by two observers.

For the purpose of analysis, each study was divided into diurnal and nocturnal periods. The diurnal period was defined as the period of recording between the documented time of waking (usually $0800 \mathrm{~h}$ ) and going to bed (usually $2300 \mathrm{~h}$ ). The nocturnal period was taken from $2300 \mathrm{~h}$ to $0800 \mathrm{~h}$, and during this time the subjects fasted.

Small bowel activity was analysed to define periods of: (i) phase 1 activity - quiescence (absence of motor activity); (11) phase 2 motor activity, characterised by irregular contractions; and (iii) phase 3 activity, regular contractile activity at a frequency of $11-13 / \mathrm{min}$, lasting at least three minutes. These represented the migrating motor complex (MMC). They were classified as either propagating, if they progressed caudally to be measured in at least three transducers, or non-propagating if they were recorded at only one transducer site (although these may have propagated over a short distance).

During phase 2 activity, the record was analysed for the presence of discrete clustered contractions (DCC), defined as rhythmic bursts of phasic contractions of duration shorter than three minutes and occurring with a much greater periodicity than phase 3 (MMC) contractions. The record was also analysed for prolonged propagated contractions $(\mathrm{PPC})$, defined as single pressure waves, propagated over at least three sites, with a duration longer than the usual ileal slow wave, often lasting 20 to 30 seconds or more, with pressures up to $100 \mathrm{~mm} \mathrm{Hg}$.

During the nocturnal fasting period of $2300 \mathrm{~h}$ to $0800 \mathrm{~h}$, the durations of phases 1,2 , and 3 activity were determined. The MMC cycle length, defined as the interval between two successive phase 3 activity fronts passing the most proximal transducer was defined. Lastly, the duration and extent of aboral propagation of each phase 3 (MMC) activity front was determined.

\section{STATISTICAL ANALYSIS}

Comparisons between patients with good and poor function for the parameters measured were performed using the Mann-Whitney $U$ Test. A probability of less than 0.05 for deriving an answer was regarded as statistically significant. threshold sensation, urgency, and maximum tolerated volume were recorded. The ex vivo distension curve for the balloon was then subtracted from the in vivo curve at each measured pressure point for each patient, to obtain the final data.

After the ambulatory motility study had been completed each patient was assessed by a video evacuation pouchogram to derive a qualitative measure of pouch size. Reservoir size was estimated by calculating the area of the reservoir on the lateral radiograph.

Data analysis

The data were down-loaded onto an Archimedes 410/1 computer for analysis. Analysis was per-

\section{Results}

\section{STOOL FREQUENCY AND VOLUME}

The number of bowel actions in 24 hours for each group of patients is shown in Table I. The total stool volume over the 24 hours was the same in both groups, but in the group with poor function the volume of each bowel action was significantly smaller.

\section{STATIC ANAL MANOMETRY}

Anal sphincter pressures were within the normal range for our laboratory in both groups of 


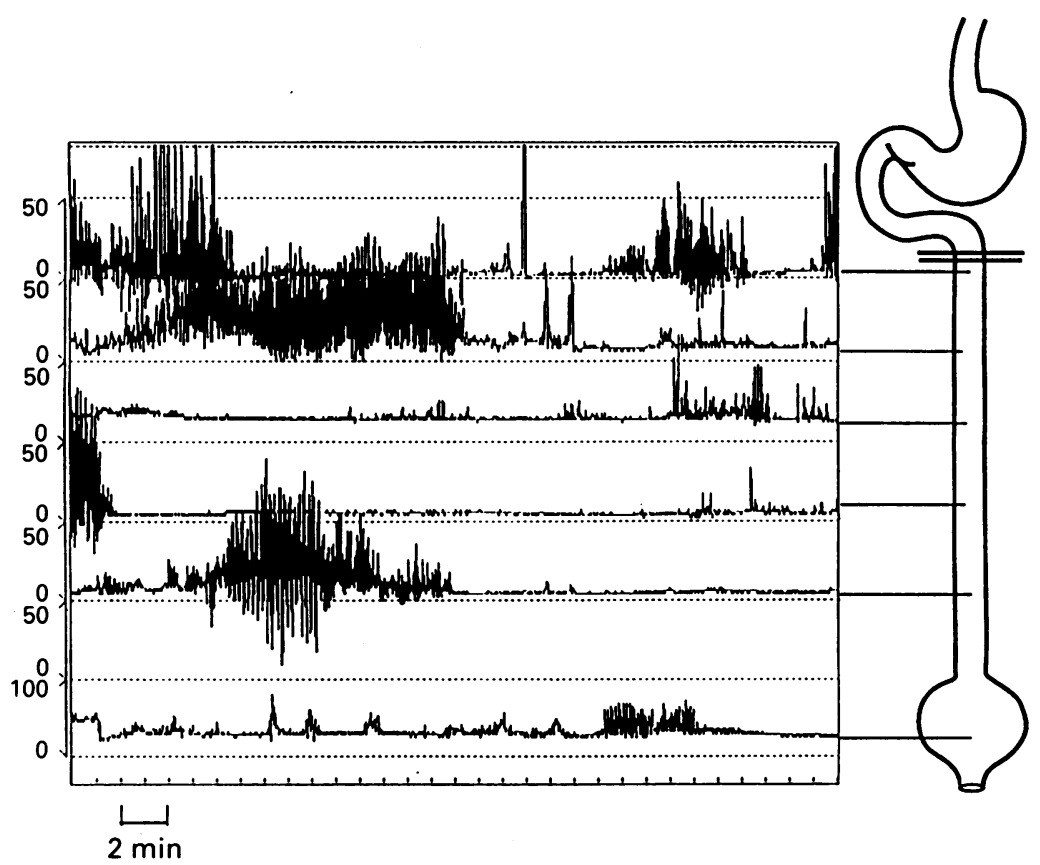

Figure 2: Migrating motor complex (MMC) in the small bowel with possible propagation of one complex into the pouch.
TABLE VII Relationship of defecation to small bowel interdigestive cycle. Number of defecations occurring during each motility phase in the two groups

\begin{tabular}{lll}
\hline & $\begin{array}{l}\text { Good function } \\
(n=5)\end{array}$ & $\begin{array}{l}\text { Poor function } \\
(n=7)\end{array}$ \\
\hline Interdigestive cycle: & 1 & \\
$\quad$ Phase 1 & 9 & 4 \\
Phase 2 & 4 & 20 \\
$\quad \begin{array}{l}\text { Phase 3 (MMC) } \\
\text { Post-cibal }\end{array}$ & 3 & 11 \\
$\begin{array}{l}\text { No of bowel motions } \\
\text { ( } \chi^{2} \text { p=0.34) }\end{array}$ & 17 & 44 \\
$\begin{array}{l}\text { Duration of reservoir activity } \\
\text { before defecation (min) } \\
\text { (Mann-Whitney p=0.003) }\end{array}$ & $9(3-30)$ & $25(5-70)$ \\
\hline
\end{tabular}

\section{RESERVOIR RADIOLOGY}

There was no significant difference $(p=0 \cdot 79)$ between the two patient groups in the area of the reservoir before emptying as measured from a lateral reservoir radiograph. The median areas were $120 \mathrm{~cm}^{2}$ (range 96-230) for the good function group and $112 \mathrm{~cm}^{2}$ (range 58-190) for the group with poor function.

\section{SMALL BOWEL MOTILITY}

patients. The two groups did not statistically differ (Table I).

\section{RESERVOIR SENSATION}

The reservoir volumes required to produce sensations of initial filling and urgency were not statistically different between the groups. The maximum tolerated volume was significantly smaller in the group with poor function (Table I).

\section{RESERVOIR COMPLIANCE}

Table II shows the compliance for each group at different volumes. There was no statistical difference between the two groups, although the range of compliance in each group was large and the number of patients at higher distension volumes was small.

TABLE V Other propagating contractions (no/h per patient) in the two groups (values, median (range))

\begin{tabular}{llll}
\hline & $\begin{array}{l}\text { Good function } \\
(n=5)\end{array}$ & $\begin{array}{l}\text { Poor function } \\
(n=7)\end{array}$ & $p$ \\
\hline Nocturnal study: & & & \\
PPC & $1.5(0 \cdot 1-7 \cdot 6)$ & $0.6(0.4-1 \cdot 5)$ & 0.53 \\
DCC & $1.4(0-4 \cdot 6)$ & $0.3(0-3.0)$ & 0.43 \\
$\begin{array}{l}\text { Diurnal study: } \\
\text { PPC }\end{array}$ & $1.0(0.5-6.5)$ & $1.3(0-2)$ & 0.88 \\
DCC & $1.1(05.6)$ & $2 \cdot 0(0-6 \cdot 5)$ & 0.88 \\
\hline PPC=prolonged propagated contractions; DCC $=$ discrete & \\
clustered contractions.
\end{tabular}

TABLE VI Migrating motor complex (MMC) characteristics of patients with good and poor function in the diurnal study (0800-2300 h) (Values, median (range))

\begin{tabular}{lccc}
\hline & $\begin{array}{l}\text { Good function } \\
(n=5)\end{array}$ & $\begin{array}{l}\text { Poor function } \\
(n=7)\end{array}$ & $p$ \\
\hline Total diurnal recording & 37 & 52 & \\
Hours per patient & $7(6-10)$ & $8(6-15)$ & \\
Total no of MMCs & 6 & 28 & $4(0-6)$ \\
No per patient & $1(0-3)$ & $5(3-6)$ & 0.05 \\
Velocity of propagation (cm/min) & $7(4-8)$ & 0.4 \\
Time to establishment of $M M C$ cycle post-cibal & $110(73-160)$ & $170(86-240)$ & 0.7 \\
\hline
\end{tabular}

\section{Fasting nocturnal activity (2300 h-0800 h) (Table} III)

During the nocturnal fasting period a total of 106 hours of recorded data were obtained in the 12 patients. There were significantly more MMCs in patients with poor function $(p=0 \cdot 03)$. This increase in number was found for both propagating and non-propagating MMCs. The median duration of the MMC cycle was shorter in patients with poor function. Although the difference did not reach statistical significance $(p=0.06)$, when the cycle was divided into its components, the phase 1 part of the cycle was significantly longer $(p=0.04)$.

The velocity of aboral propagation of the MMC activity front was similar in the two groups. There were no significant differences between the groups in the distance of propagation of the MMC, the proportion of MMCs reaching the distal transducer, or the originating sites of the MMCs (Table IV). These features suggest that the characteristics of the MMCs were similar for the two groups of patients. Figure 2 shows multiple MMCs in a patient with poor function.

No difference was found in the number of PPCs or DCCs between the two groups (Table $\mathrm{V})$.

Daytime activity $(0800 h-2300 h)$ Table VI) A total of 89 daytime hours (median $7 \cdot 5$ hours per patient) of recording was analysed for both groups. A large proportion of this time was spent in the postprandial state; therefore it was not possible to evaluate the length of MMC cycles during the day in either group. The total number of MMCs occurring in the patients with poor function, however, was substantially greater $(p=0.05)$ than that in patients with good function. Other measured $M M C$ variables were not significantly different between the groups.

There was no significant difference $(p=0 \cdot 88)$ 
in the number or site of origin of daytime PPC or DCC. These contractions, however, were difficult to discern postprandially amidst the intense phase 2 activity.

\section{PROPAGATION OF SMALL BOWEL MOTILITY}

ACTIVITY INTO THE RESERVOIR

During the entire recording period there were 120 phase 3 (MMC) fronts recorded. Two of these (one in a patient with good function and one with poor function) seemed to occur soon after an MMC had traversed the small bowel, and these may have propagated into the pouch (Fig 2). At the most, therefore, less than $2 \%$ of all MMCs propagated into the reservoir. No DCCs were transmitted into the reservoir. In one subject only, who had good function, multiple PPCs were transmitted into the reservoir (Fig 3).

\section{SMALL BOWEL MOTILITY AND DEFECATION}

The sensation of urge to defecate was not associated with any recognisable change in the small bowel motility pattern. But on $92 \%$ of occasions the sensation of urgency occurred during phase 2 or post-cibal motility activity. Not all of these resulted in defecation. In both groups, $68 \%$ of defecation occurred during late phase 2 activity or phase 3 (MMC) activity (Table VII).

Defecation occurred during the night $(2300 \mathrm{~h}-$ $0800 \mathrm{~h}$ ) on seven occasions in patients with good function and on 15 occasions in patients with poor function. In those with good function, five defecations occurred during phase 2 and two when an MMC was in, or had just passed, the distal small bowel. In those with poor function, two defecations occurred during phase 1 , six during phase 2, and seven close to an MMC in the distal small bowel. Thus, there did not seem to be a constant relationship at night between the arrival of a phase $3 \mathrm{MMC}$ in the pouch and

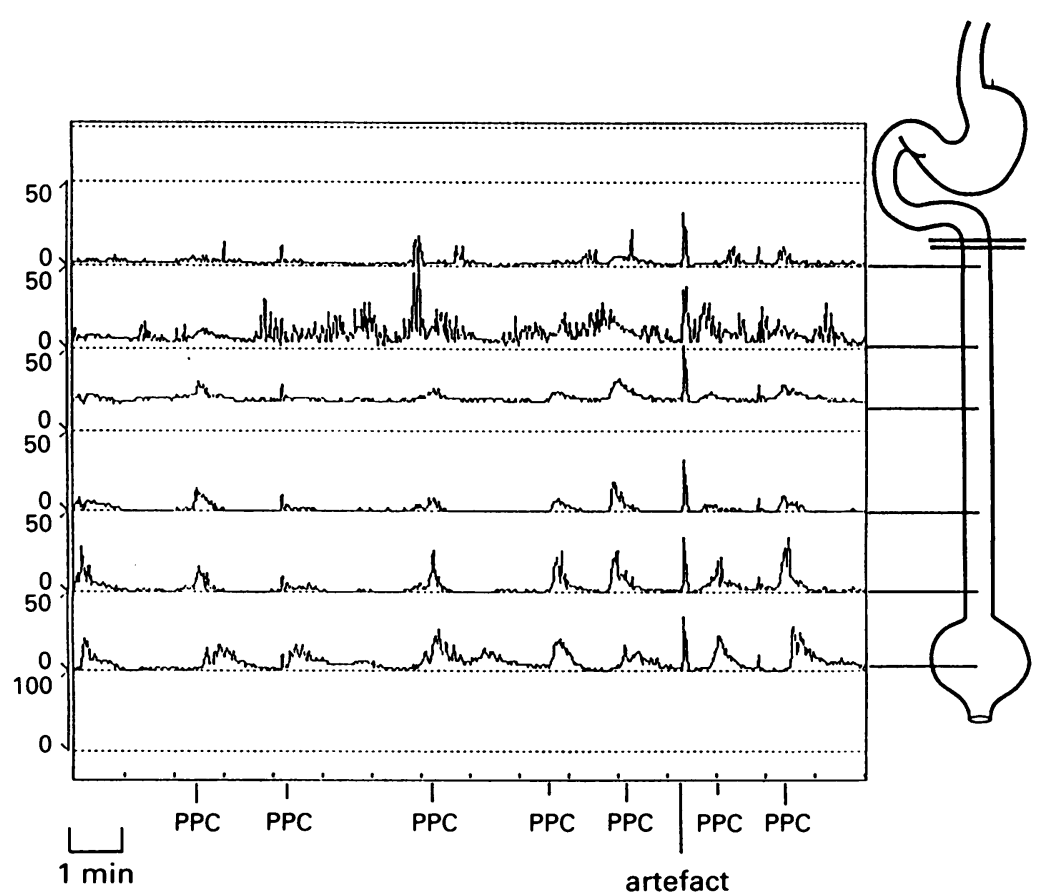

Figure 3: Multiple prolonged propagated contractions (PPC) propagating quickly down the small bowel and entering the pouch. defecation. Defecation usually occurred during phase 2 or phase 3 activity, which are the times when transit occurs. This is despite the short duration of phase 2 activity at night in these patients (Table III).

Reservoir motility changed from quiescence to increased contractility before each defecation. This period of increased activity was significantly longer $(p=0.003)$ in the group with poor function (Table VII).

\section{SMALL BOWEL MOTILITY IN RESPONSE TO} ARTIFICIAL RESERVOIR DISTENTION

When the reservoir was artificially distended during the compliance study at the completion of the ambulatory period, there was no observed change in the recording pattern of the small bowel proximal to the reservoir.

\section{RELATIONSHIP OF RESERVOIR CAPACITY TO}

\section{NOCTURNAL SMALL BOWEL MMC FREQUENCY}

There was no significant correlation between the frequency of nocturnal MMCs and the maximum tolerated volume of the reservoir for patients with good function $(\mathrm{r}=0.68, \mathrm{p}=0.21)$, poor function $(r=0 \cdot 10, p=0 \cdot 84)$, or for all patients $(\mathrm{r}=-0.55, \mathrm{p}=0.63)$.

\section{Discussion}

The study has shown significant differences in the small bowel motility pattern between patients with good and poor reservoir function. In particular the number of MMCs during the nocturnal fasting period was noticeably increased in those with poor function. This increase involved both propagating and non-propagating MMCs. As a result the interval between MMCs was shorter in those with poor function.

These differences occurred despite a total stool volume which was almost identical in the two groups of patients. The altered pattern of small bowel motility is therefore unlikely to be related to an increased fluid or secretory load.

These differences in small bowel motility may be related to increased stool frequency in several ways. The altered motility may be primary, resulting in more frequent deliveries of small volumes of fluid to the reservoir. This motility difference may have preceded the creation of the reservoir. Normally there is a substantial variation between individuals in the number of frequency of the MMCs they generate. This may be of no or little consequence if the colon, with its large absorptive and reservoir capacity, is in situ, but removal of the colon and its substitution with the ileoanal reservoir may unmask the effect of this individual variation in small bowel behaviour.

Evidence supporting differences in small bowel motility that result in different patterns of defecation comes from Kellow et $a l$ who performed 24 hour ambulatory small bowel motility studies in 20 patients with the irritable bowel syndrome. Those with diarrhoea predominant syndrome had significantly more frequent small bowel MMCs than healthy control subjects.

A second possibility is that the difference in 
small bowel motility occurs after creation of the ileonal reservoir. Differences in reservoir function, which manifest as different frequencies of evacuation, could then also feed back to the proximal small bowel via intrinsic neural pathways to modify its behaviour. A prospective study of small bowel motility before reservoir creation would be the only way to establish which of these processes is responsible.

A further possible explanation for the differences in reservoir function and small bowel motility is that the two are epiphenomena. Differences in bowel frequency may relate to differences in reservoir construction or function simultaneous with, but not related to, differences in small bowel function.

Two previous studies of small bowel motility in patients following restorative proctocolectomy failed to show any difference in MMC frequency. ${ }^{89}$ In both studies, however, patients with an ileoanal reservoir were compared with normal healthy subjects without reservoirs, and no discrimination on the basis of clinical status was attempted. In the study by Chaussade et $a l,{ }^{8}$ only jejunal motility was considered and was investigated for a period of time (four hours) which would be insufficient to detect differences in small bowel function. In the study by Stryker et $a l,{ }^{9}$ the non-ambulant recordings were for a longer period of time and both jejunal and ileal motility were studied. The periodicity and other parameters of the MMC were not significantly different between patients and healthy subjects.

In the current study, the total stool volume and radiological size of the reservoir in the two groups were similar. Differences in the maximum tolerated volume may therefore relate to altered reservoir sensitivity rather than reservoir size. This altered sensitivity may co-exist with the small bowel motility disturbance which we have observed.

When testing reservoir distension characteristics, the volume required to elicit an initial sensation and a sense of urgency were also similar in both patient groups. The volume required to elicit a sense of urgency was well above the relatively small volume passed by the patients with poor function. Therefore, although the reservoirs with poor function had a reduced maximum capacity, this may not be a critical factor as stool volumes in both groups of patients were well within the maximum tolerated volumes.

The major difference defined in this study between patients with good and poor function relates to nocturnal motility patterns. Unfortunately, daytime motility patterns are far harder to compare between individuals and groups. Fasting data are easier to compare because of the clear identification of phase 3 activity (MMC); fasting patterns of motility rarely occur during the day for long periods because of meals and snacks. We could have fed our subjects less frequently and in a standardised way, but we wanted to record their intestinal function under normal physiological circumstances. There did appear to be daytime differences in small bowel function between the two groups, but further studies may be required to characterise this further.
Using the nocturnal study period as an indication of fasting motility patterns has also been validated previously. ${ }^{10}$ As well as the nocturnal period being the most easily reproducible, there is some relationship to function. All patients with poor function had bowel actions during the night, whereas patients with good function seldom had a bowel action then.

Although the MMC participates in the propulsion of chyme, other motor events occurring during phase 2 activity are also likely to propel intestinal contents. Two such types of contractions include PPCs and DCCs. We found no difference in the frequency, propagating velocity, or the originating position in the small bowel of either of these contraction patterns between the two groups of patients. During the night recording there were fewer of these contractions recorded in both groups of patients; this was to be expected as most occur during phase 2 activity, which is virtually absent during sleep. The decrease in this type of activity during sleep has been documented previously.

Although small bowel motility patterns were transmitted into the reservoir, this occurred only rarely and did not seem to influence function. Stryker $e t a l$, recording from the small bowel and reservoir simultaneously, did not record the propagation of MMCs into the reservoir in any patient. ${ }^{9}$ In our series, of the $96 \mathrm{MMCs}$ recorded, only two (2\%) seemed to be transmitted into the reservoir (one from each group). In a study of proximal and terminal ileal motility in healthy controls, one third of MMCs recorded in the upper small bowel reached the proximal ileum but only $2 \%$ reached the ileocaecal valve.

Two episodes of rhythmic non-transmitted MMC-like activity in the reservoir were recorded in this study, both episodes occurring in patients with poor function. These episodes of rhythmic reservoir contraction have been previously documented by our group. ${ }^{4}$ Only one PPC propagating into a reservoir was recorded - in a patient with good function. No DCCs were observed to propagate into the reservoir. It therefore seems that small bowel motility is not commonly propagated into the reservoir directly, and that differences in propagation are not responsible for differences in clinical function.

Differences in reservoir motor activity in response to reservoir distension in patients with good and poor function have been noted previously. O'Connell et al showed that with artificial distension of the reservoir, contraction waves within the reservoir occurred at a lower distending volume in subjects with poor function. ${ }^{12}$ Miller et al showed increased reservoir motility in subjects with poor function ${ }^{13}$ and we have previously shown that some patients with poor function have an increased frequency and amplitude of rhythmic reservoir waves. ${ }^{6}$

In this study the pattern of reservoir motor activity seemed to be independent of the pattern of small bowel motility proximal to it. But increased reservoir activity preceding defecation was associated with late phase 2 or phase 3 (MMC) activity in the small bowel proximal to the reservoir. This probably reflects reservoir filling, as most of the aboral movement of intestinal contents occurs during phase 2 and 
phase 3 motor activity. Any assessment of reservoir activity should bear in mind that the pressure probe may miss some motor events because of the large cavity size.

The sensation of an urge to defecate was always associated with increased reservoir activity, which is therefore likely to reflect distension of the reservoir and not proximal small bowel motility. Defecation occurred by a valsalva manoeuvre.

In addition to the pattern of intestinal motility, changes in pouch tone, which relate to altered proximal small bowel motility, may also be important contributors to function. A barostat positioned in the pouch would be required to assess this.

In summary, differences in small bowel motility have been identified in patients with high and low bowel frequency after ileoanal reservoir creation. Futher studies are required to determine whether these existed before reservoir creation.

1 Symposium. Restorative proctocolectomy with ileal reservoir.

Int f Colorect Dis 1986; $1: 2-20$.
2 Nicholls RJ. Restorative proctocolectomy with various types of reservoir. World f Sung 1987; 11: 751-62.
3 Stryker SJ, Phillips SF, Dozois RR, Kelly KA, Beart RW Jr. Anal and neorectal function after ileal pouch-anal Anal and neorectal function after

4 Levitt MD, van der Sijp JRM, Kamm MA, Nicholls RJ. Prospective pouch and anal ambulatory manometry to characterise good and bad function. Gut 1990; 31: Al169.

5 Henry MM, Swash M. Coloproctology and the pelvic floor. 2nd ed. London: Butterworth-Heinemann, 1992.

6 Levitt MD, Kamm MA, Groom JS, Hawley PR, Nicholls RJ. Ileoanal pouch compliance and motor function. $\mathrm{Br} \mathcal{F}$ Surg 1992; 79: 126-8.

7 Kellow JE, Gill RC, Wingate DL. Prolonged ambulan recordings of small bowel motility demonstrate abnormalities in the irritable bowel syndrome Gastroenterology 1990; 98: 1208-18.

8 Chaussade S, Merite F, Hautefeuille $M$, Valleur P, Hautefeuille P, Couturier D. Motility of the jejunum after proctocolectomy and ileal pouch anastomosis. Gut 1989; 30: proctoco.

9 Stryker SJ, Borody TJ, Phillips SF, Kelly KA, Dozois RR, Beart RW. Motility of the small bowel after proctocolectomy Beart RW. Motility of the small bowel after proctocolectomy

10 Kumar D, Idzikowski C, Wingate DL, Soffer EE, Thompson P, Siderfin C. Relationship between enteric migrating motor complex and the sleep cycle. Am F Physiol 1990; 259. G983-90.

11 Quigley EMM, Borody TJ, Philips SF, Wienbeck M, Tucke RL, Haddad A. Motility of the terminal ileum and ileocaecal sphincter in healthy humans. Gastroenterology 1984; 87: 857-66.

12 O'Connell PR, Stryker SJ, Metcalf AM, Pemberton JH, Kelly A. Anal canal pressure and motility after ileoanal anastomosis. Surg Gynae Obstet 1988; 166: 47-54.

13 Miller R, Orrom WJ, Duthie G, Bartolo DCC, Mortensen NJMcC. Ambulatory anorectal physiology in patients folJMcC. Ambulatory anorectal phys fogy in patients folowing restorative proctocolectomy for ulcerative colitis: 895-97. 